\title{
Root Canal Therapy of a Maxillary First Molar with Five Root Canals: Case Report
}

\author{
Amauri FAVIERI ${ }^{1}$ \\ Fabiana Gama Benevides de BARROS 2 \\ Luís Claudio CAMPOS² \\ ${ }^{1}$ Department of Endodontics, Faculty of Dentistry, Unigranrio, Rio de Janeiro, RJ, Brazil \\ ${ }^{2}$ Department of Endodontics, Faculty of Dentistry, Estácio de Sá University, Rio de Janeiro, RJ, Brazil
}

\begin{abstract}
This paper reports the case of a maxillary left first molar that presented three root canals in the mesiobuccal root. Root canal therapy and case management are described. Features like wide crown access, adequate illumination and use of exploring files where important for successful completion of the endodontic treatment.
\end{abstract}

Key Words: internal anatomy, endodontic treatment, maxillary first molar.

\section{INTRODUCTION}

Knowledge of the internal dental morphology is a complex and extremely important point for planning and performing of endodontic therapy. The several anatomical variations existing in the root canal system may contribute for failure of root canal therapy, mainly in teeth with pulp necrosis. Several authors have attempted to clarify this topic and have proposed new techniques to provide a broader description of the anatomy of permanent teeth.

The first study describing the internal dental anatomy dates back to the 19th century (1). In the beginning of the 20th, Okumura (2) published his revolutionary study about the transformation of teeth into transparent blocks, revealing complex wefts that were part of root canals. Weine et al. (3) observed that failures related to the mesiobuccal root of maxillary molars jeopardized the success of the endodontic treatment and found that teeth with a fourth canal occurred more frequently than those with three canals (51.5\% versus $48.5 \%)$. Since then, studies have investigated the endodontic significance of canal configuration in the mesiobuccal root of maxillary first molars using different methods and found similar results to those of Weine et al. (3). Hession (4) compared the canal morphology before and after instrumentation and concluded that the number of canals usually equals the number of roots. The greatest variations observed were the presence of two canals in the mesiobuccal root of maxillary molars, canals in the furcation area and presence of lateral and accessory canals.

A detailed investigation about anatomic variations occurring in 2,400 extracted human permanent teeth submitted to clearing procedures was carried out (5) focusing on the following features: number and types of canals, ramifications associated to the main canal, apical foramen location, presence of transversal anastomoses and frequency of apical deltas. The author classified the canal configurations in 8 groups that were mostly related to the opening and exit of the main canals. Pécora et al. (6) developed a new method to make human teeth transparent by using bisphenol A epoxy resin. In a study with 208 maxillary first molars, Fogel et al. (7) examined the configuration of the canals located in the mesiobuccal root using a surgical telescope, manual optical fibers and endodontic explorers. The authors concluded that accurate location of these canals depends on use of

Correspondence: Prof. Dr. Amauri Favieri, R. Visconde de Pirajá, 303/706, Ipanema, 22410-001 Rio de Janeiro RJ, Brasil. Tel: +55-212521-1477. Fax: +55-21-2521-1477. e-mail amaurifavieri@ibest.com.br 
magnification, adequate lighting and modified access, and found that $71.2 \%$ of the teeth had treatable canals and $31.7 \%$ of them had two separate foramina. Rhodes et al. (8) compared two nickel-titanium instrumentation techniques under microcomputed tomography and obtained detailed three-dimensional views of the root canal system and its multiple anatomic variations. Çaliskan et al. (9) used an operating microscope to analyze the prevalence and location of mesiobuccal canals in 45 maxillary molars and observed that this resource increased considerably the chances of location and consequently treatment of mesiobuccal canal-2. In addition, mapping of this second mesiobuccal canal allowed determining the average distance between both mesiobuccal canals. A study about dental anatomic variations (10) revealed a high incidence of two canals in the mesiobuccal root of maxillary first molars. They also emphasized that when this second canal is not found, the endodontic treatment might fails.

This paper reports the case of a maxillary left first molar that presented three root canals in the mesiobuccal root. Root canal therapy and case management are described.

\section{CASE REPORT}

A 15-year old Caucasian male patient was referred to the Semiology Clinic at Estacio de Sá University (Rio de Janeiro, RJ, Brazil) for endodontic treatment of tooth 26 . The tooth was asymptomatic and sealed with a zinc oxide and eugenol dressing. Thermal sensitivity tests

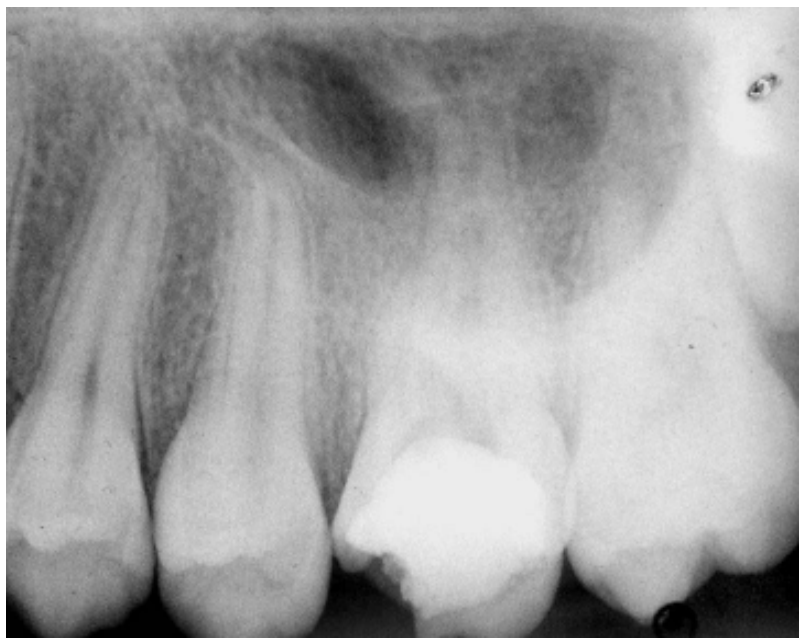

Figure 1. Initial radiograph. indicated pulp necrosis. Neither fistulae nor edema was observed. The periapical radiograph showed a small area of thickened periodontal ligament around the root apexes (Fig. 1).

Local anesthetic was given and the operative field was isolated with a rubber dam for crown access. Exploration of root canal entrances revealed 3 distinct canals in the mesiobuccal root, 1 canal in the distobuccal root and 1 canal in the palatal root, which were further confirmed by the radiograph for working length determination (Fig. 2). Thereafter, the canals were chemomechanically prepared according to the ARM (alternated rotary motions) technique (11) using 2\% sodium hypochlorite as irrigating solution. After exploring the 5 canals with \#06, \#08 and \#10 K-files (Dentsply, Petrópolis, RJ, Brasil), root canal access was made with \#2, \#3 and \#4 Gates-Glidden drills (Maillefer, Ballaigues, Switzerland). Based on tooth length shown in the initial radiograph, \#15 K-files (Dentsply) were introduced in the mesiobuccal-1, mesiobuccal-2 and mesiopalatal canals, while \#20 and \#25 K-files (Dentsply) were introduced in the distobuccal and palatal canals, respectively, to determine the working length simultaneously at $1 \mathrm{~mm}$ short of the apex. Apical preparation of the mesiobuccal canal-1, mesiobuccal canal-2 and mesiopalatal canals was completed with \#35 nickel-titanium files (Dentsply), followed by cleaning of the final portion of the canals at the patency limit with a \#10 K-file (Dentsply). Apical preparation of the distobuccal and palatal canals was performed with \#35 and \#45 K-files (Dentsply), respectively.

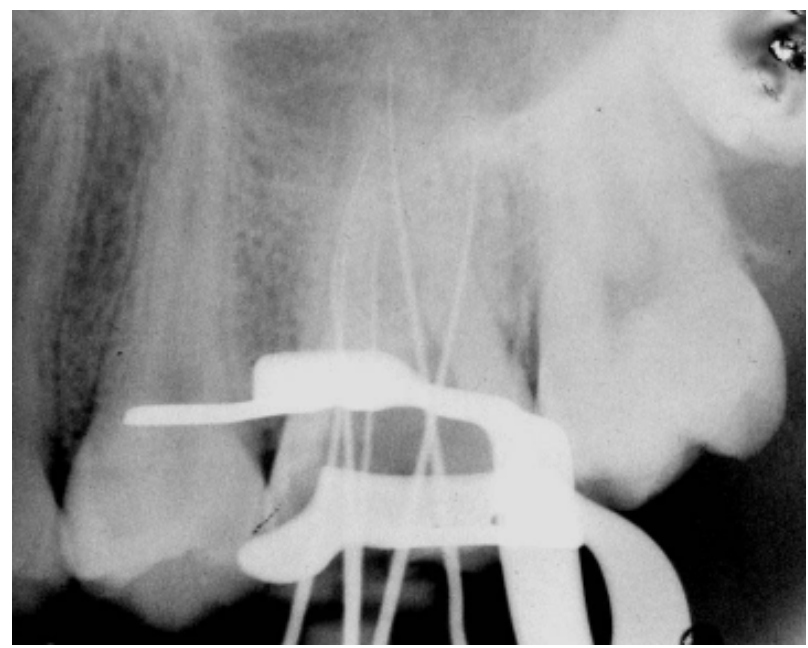

Figure 2. Radiograph for working length determination. 
Thereafter, four scaled 1-mm recessions were made in a crown direction of all canals. Chemomechanical preparation was completed in the first session. The canals were flushed with EDTA for 3 min under continuous stirring with a file, rinsed, dried and filled with a paste prepared with calcium hydroxide, paramonochlorophenol and glycerin, which was used as an intracanal medication. Root canal access was sealed with a zinc oxide and eugenol dressing. After 7 days, the canals were emptied, copiously flushed with $2 \%$ sodium hypochlorite under stirring with a \#15 K-file (Dentsply) and dried with paper points. Main guttapercha cones were selected for each canal (Fig. 3) and all canals were filled using the lateral condensation technique. A final radiograph was taken to confirm the completeness and extension of root filings. The tooth was provisionally sealed and the patient was referred for restorative treatment.

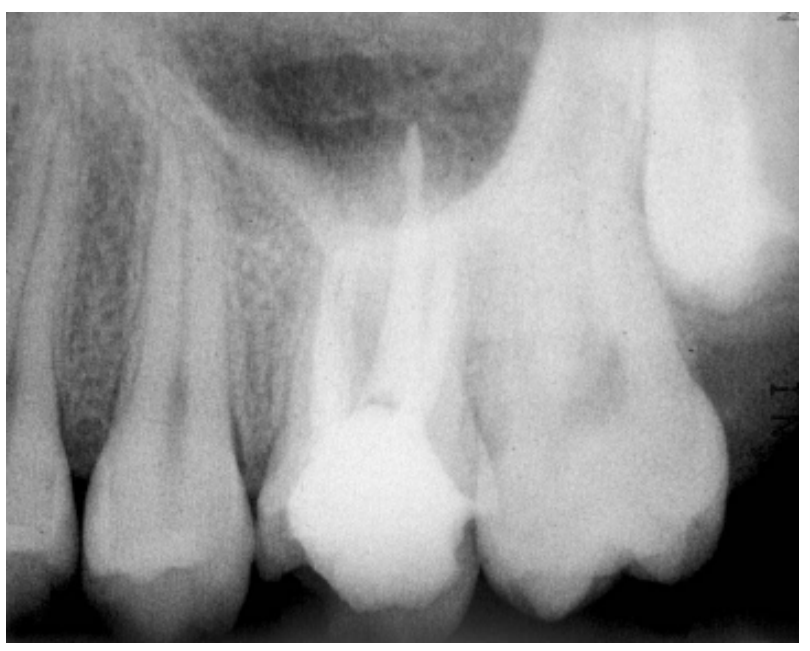

Figure 3. Final radiograph.

\section{DISCUSSION}

The variations in dental anatomy play an important role in root canal therapy. A great predominance of two very close canals in the mesiobuccal root of maxillary molars has been demonstrated (7). Despite the current high success rate achieved in endodontic treatments, the mesiobuccal root is still associated to a considerable number of failures due to the difficulty in locating and filling the second and/or third mesiobuccal canals $(5,7)$. On account of this, root canal therapy of these teeth should be carried out using angulated x-rays $(12,13)$, efficient explorers, wider crown accesses (13), adequate lighting and, whenever possible, image magnification $(14,15)$. In the case reported in this paper, the mesiobuccal root presented a moderate curvature with three atresic canals. The mesiobuccal canal-1 had one opening and one exit (Vertucci's first class), while the mesiobuccal canal-2 and the mesiopalatal canal presented two openings and one exit (Vertucci's fourth class).

The instrumentation of these canals was carried out with nickel-titanium files. These instruments are indicated in these cases due to their flexibility and because they pose lesser risks of step formation or perforations. The instrumentation technique used in this study (ARM) recommend a wide access to the middle and cervical thirds, which facilitated the cleaning of the apical third and the filling of the root canals (11).

\section{RESUMO}

Este artigo relata o caso clínico de um primeiro molar superior esquerdo que apresentava um terceiro canal na raiz mésiovestibular. O tratamento endodôntico e o manejo do caso são descritos. Fatores como amplo acesso coronário diferenciado, iluminação adequada, além do uso de instrumentos exploradores foram essenciais para o sucesso do tratamento endodôntico.

\section{REFERENCES}

1. Carabelli G. Anatomie des Mundes. Viena: Braumüller \& Seidel; 1842.

2. Okumura T. Anatomy of the root canals. J Am Dent Assoc 1927;14:632-635.

3. Weine FS, Healey HJ, Gerstein H, Evanson L. Canal configuration in the mesiobuccal root of the maxillary first molar and its endodontic significance. Oral Surg Oral Med Oral Pathol 1969;28:419-425.

4. Hession RW. Endodontic Morphology. An alternative method of study. Oral Surg Oral Med Oral Pathol 1977;44:456-462.

5. Vertucci FJ. Root canal anatomy of the human permanent teeth. Oral Surg Oral Med Oral Pathol 1984;58:589-599.

6. Pécora JD, Woelfel JB, Sousa Neto MD. Morphologic study of the maxillary molars. 1. External anatomy. Braz Dent $\mathrm{J}$ 1991;2:45-50.

7. Fogel HM, Christie WH, Peikoff MD. Canal configuration in the mesiobuccal root of the maxillary first molar: a clinical study. J Endod 1994;20:135-137.

8. Rhodes TR, Ford TR, Lynch JA, Liepins PJ, Curtis RV. A Comparison of two nickel-titanium instrumentation techniques in teeth using microcomputed tomography. Int Endod J 2000;33:279-285.

9. Çaliskan MK, Pehilvan Y, Sepetçioglu F, Türkün M, Tuncer S. Root canal morphology of human permanent teeth in a Turkish population. J Endod 1995;21:200-204. 
10. Pécora JD, Woelfel JB, Sousa Neto MD, Issa EP. Morphologic study of the maxillary molars. Part II: Internal anatomy. Braz Dent J 1992;3:53-57.

11. Siqueira JF Jr, Rocas IN, Santos SR, Lima KC, Magalhães FA, De Uzeda M. Efficacy of instrumentation techniques and irrigation regimens in reducing the bacterial population within root canals. J Endod 2002;28:181-184.

12. Weine FS, Eskoz N. Canal configuration of the mesiobuccal root of the maxillary second molar. J Endod 1995;21:38-42.
13. Weller RN, Hartwell GR. The impact of improved access and searching techniques on detection the mesiolingual canal in maxillary molars. J Endod 1989;15:82-83.

14. Kim S. Principles of endodontic microsurgery. Dent Clin North Am 1997;41:481-497.

15. Kim S, Baek S. The microscope and endodontics. Dent Clin North Am 2004;48:11-18.

Accepted June 24, 2004 